\title{
Article
}

\section{"Honour"-based violence in a British South Asian community}

Khan, Roxanne, Saleem, Shamam and Lowe, Michelle

Available at http://clok.uclan.ac.uk/17808/

Khan, Roxanne ORCID: 0000-0002-3485-2450, Saleem, Shamam and Lowe, Michelle (2018) "Honour"-based violence in a British South Asian community. Safer Communities, 17 (1). pp. 11-21. ISSN 1757-8043

It is advisable to refer to the publisher's version if you intend to cite from the work. http://dx.doi.org/10.1108/SC-02-2017-0007

For more information about UCLan's research in this area go to http://www.uclan.ac.uk/researchgroups/ and search for < name of research Group>.

For information about Research generally at UCLan please go to http://www.uclan.ac.uk/research/

All outputs in CLoK are protected by Intellectual Property Rights law, including Copyright law. Copyright, IPR and Moral Rights for the works on this site are retained by the individual authors and/or other copyright owners. Terms and conditions for use of this material are defined in the policies page.

\section{CLoK}

Central Lancashire online Knowledge www.clok.uclan.ac.uk

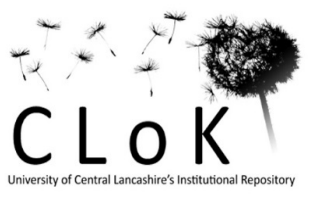


'Honour'-based violence in a British South Asian community

\begin{tabular}{|r|l|}
\hline Journal: & Safer Communities \\
\hline Manuscript ID & SC-02-2017-0007.R1 \\
\hline Manuscript Type: & Research Paper \\
\hline Keywords: & male victims, Muslims, police, self-harm, suicide, 'honour' crimes \\
\hline \multicolumn{2}{|l}{} \\
\hline
\end{tabular}

SCHOLARONE ${ }^{\text {m }}$

Manuscripts 


\begin{abstract}
Purpose: This study explored attitudes towards, and victimisation experiences of, 'honour'based violence (HBV) in a reportedly vulnerable population in the UK.

Methodologies: A convenience sample of 216 participants were recruited from a local community in England; the majority were young (mean age=21.93), Indian or Pakistani (85\%), Muslim (96\%), females (67\%).
\end{abstract}

Findings: Although gender differences were found for attitudes towards one aspect of HBV (namely, forced marriage), these were not significant. While HBV victimisation affected only a small proportion of this sample, when it was reported, the effects were serious and included anxiety, attempted suicides, and running away from home. This highlights the need to identify and safeguard vulnerable groups without stigmatising whole communities.

Value: These findings contribute to the scarce literature available on HBV in British communities, and highlight a need for culturally-aware emergency and health service provision.

Keywords: male victims; Muslims; police; self-harm; suicide; 


\section{'Honour'-based violence in a British South Asian community}

Each year, a significant number of Britons are murdered in the name of so called 'honour' [1]. At approximately one homicide per month, Britain has the highest degree of 'honour' killings in Europe (Foreign \& Commonwealth Office, 2004). A number of high-profile 'honour'-killings, both nationally and globally, has renewed debates on how to better identify and protect victims at risk of 'honour'-based violence (HBV). This study adds to the literature by recruiting participants from diasporic populations in a local community in the north of England in which HBV is reported to occur at a high rate, to ascertain their attitudes towards, and experiences of, HBV victimisation.

\section{'Honour' based violence (HBV): a working definition}

In the UK, HBV is a term used to define criminal acts committed in defence of, or to protect the honour of, an individuals' family and/or community (Crime Prosecution Service, 2014). A wide-range of HBV acts are reported that vary in degrees of severity, including psychological, physical, and sexual abuse, withdrawal from school, isolation, imprisonment, kidnapping, and forced marriage (Schlytter \& Linell, 2009). Unsurprisingly, there are many negative outcomes associated with HBV victimisation, including depression, self-harm, and suicide-attempts (Brandon \& Hafez, 2010).

\section{The prevalence of 'honour' crimes}

'Honour' killings are projected to have an annual global prevalence rate of approximately 5,000 , yet this figure is estimated to be a vast underestimation (Al Gharaibeh, 2016). Mostly, it is argued that 'honour' crimes are unrelated to a specific religion or culture, and globally, cases are noted across a wide territorial base. Despite its pervasive and historic roots, in recent times HBV is reported most commonly in rural areas and within Muslim communities worldwide (Chesler, 
2010; Grzyb, 2016).

The first nationwide statistics collated on HBV in the UK showed that 2,823 cases were reported to 39 police forces during 2010, illustrating a wide dispersion of 'honour' crimes across the nation (BBC News, 2011). A national inspection of UK police forces revealed that there were $251 \mathrm{HBV}$ referrals from 2014 to 2015 (HMIC, 2015). An independent examination of police HBV recordings, across 39 of the 52 forces in the UK, showed that 11,000 cases had been recorded between 2010-2014 (IKWRO, 2014). Due to underreporting, definitional problems and inconsistency of recording, these figures are unlikely to represent the true extent of HBV victimisation in the UK. Indeed, it is estimated that in 2012 alone, over one-fifth of the UK's police forces did not successfully flag-up or record data on 'honour' crimes (IKWRO, 2014). Even without reliable baseline data, these prevalence rates establish HBV as a problem inherent in the lives of a large number of British families (Brandon \& Hafez, 2010).

\section{Vulnerability to HBV: identifying populations at risk in the UK}

It is clear from whatever data is available that in the UK, victims are typically young, South Asian women (Dyer, 2015). This demographic-profile is valuable in efforts to identify victim-vulnerability. It is notable, for example, that this 'at-risk' group can be characterised as having diasporic origins, with families likely to have migrated from patriarchal, collectivistic cultures in South Asia where the use of aggression is reportedly tolerated if used to protect a family's honour (or izzat) from shame (or sharam) [2] (Gangoli, McCarry, \& Razak, 2009). This provides a cultural-context for figures reported in the 2011 census which show that currently, India ( $n=1.4$ million; $2.5 \%)$ and Pakistan $(n=1,125,000 ; 2 \%)$ represent two of the top three countries of birth for the foreign-born currently in the UK (Census Statistics Bulletin, 2013). While this represents just $5.5 \%$ of the total UK population, it might help to explain how in some 
collectivist migrant communities, HBV might be a covert but ubiquitous practice amongst a minority.

\section{Perceptions and experiences of HBV: an overlooked and under-researched form of abuse}

Due to the power of 'izzat' and 'sharam' in South Asian communities, efforts to understand the motives underpinning 'honour' crimes might be restricted due to concerns of cultural insensitivity. As a result, it has been argued that academic and professional attempts to address HBV are, at times, superficial (Chesler, 2016). This in turn could also explain why empirical research using South Asian communities in the UK remains a scant resource. It is also noteworthy that much of the published HBV studies of British populations are based on either police statistics, small-group interviews, or case studies of women identified as victims. However, focusing on the extreme representations of HBV provides only a partial insight and understates more routine and indirect, but equally damaging, perceptions and behaviour, thus impinging on wider understanding. This is important to understand because theoretical models link people's attitudes in support of HBV with their abusive behaviour (see Roberts, 2014). Therefore, any research support for emerging theoretical paradigms will be useful for explaining the seemingly inexplicable actions of perpetrators, and inaction of victims who often do not seek help from external services when they or their family are faced with adverse, injurious, and sometimes life-threatening situations as a result of $\mathrm{HBV}$.

\section{Attitudes towards HBV and killing: gender differences}

Arguably, HBV is incomparable with other forms of interpersonal abuse as it is common for multiple perpetrators (both male and female) to aggress against one or more victims, who are often close family (including mothers) or at least community members (Aplin, 2017; Chesler, 2015). It is useful, therefore, to re-examine the existing research that shows in comparison to females, males are generally more approving of violence and less disapproving of other men who 
use violence against women (Khan, 2017). Evidence from Asian or Arab populations show a similar pattern; for example, in a survey of 500 British Asians aged 16-34 years, a greater proportion of males $(6 \%)$ condoned 'honour' killings in comparison to females $(1 \%)$ (ComRes, 2012). Also, a twofold gender difference was found with 856 school children (mean age 14.6 years) in Jordan, where boys (46.1\%) were more likely to endorse the use of 'honour' killings than girls (22.1\%) (Eisner \& Ghuneim, 2013).

Even within healthcare settings, attitudinal differences have been found in relation to gender; for example, although low in number, in a sample of 225 nursing students (aged 20-25 years) in Turkey, a greater proportion of males justified 'honour' crimes (Can \& Edirne, 2011). However, an older general public sample survey ( $n=601$; mean age 35.4 years; aged18-71 years) in Pakistan, revealed that regardless of gender, the majority (57.1\%) approved of a husband's 'honour' killing of his wife as a result of her extramarital affair (Shaikh, Shaikh, Kamal, \& Masood, 2010).

\section{Understanding HBV from a community perspective}

Little research has explored both male and female attitudes towards, and experiences of, HBV in local communities in England. The advantage of localised studies is the degree to which they look at specific populations. Due to the heterogeneity of ethnic South Asian populations across the UK, from one community to another, there is value in identifying trends for different populations. For example, there may be differences between populations in general attitudes towards violence that may arise from acculturation (Bhanot \& Senn, 2007); this might be based on same-migrant population size or degrees of wider community integration. While local studies cannot be viewed as nationally representative, their greatest value results from subsuming local investigations within broader studies, allowing estimates what the general trends might be.

\section{Research aims}


This exploratory study investigated the attitudes towards, and experiences of HBV in a convenience sample of British South Asian males and females from a local community in Lancashire, located in the north of England. The rationale for recruiting participants from this specific community stemmed from the high victimisation rates reported to Lancashire police; in 2010, this was fourth highest rate across 52 UK police forces. The influence of participant gender and HBV victimisation experiences upon perceptions of HBV were explored in some depth. Awareness of HBV support (welfare and emergency) services, and perceived barriers to services as a result of $\mathrm{HBV}$ victimisation were also examined.

\section{Method}

\section{Participants and Procedure}

A total of 216 British South Asian participants (71 males; 145 females), with an age range of 16-54 years $(M=21.93$ years; $S D=6.68)$ took part in the study. Further demographic details and sample characteristics are shown in Table 1 . The majority of participants were either Pakistani (43.1\%) or Indian (41.9\%). A further 7.9\% were Bangladeshi, while the remaining 7\% were of mixed South Asian ethnicity. The vast majority of participants ascribed to a religion (96.8\%), with the majority (93.8\%) stating that their religious affiliation was with Islam. The remaining $4.7 \%$ were Hindu, Sikh (0.5\%), Christian $(0.5 \%)$ or other $(0.5 \%)$.

Participants were recruited to complete questionnaires using purposive sampling techniques on the basis of convenience and availability of respondents, bearing in mind difficulties of sampling minority ethnic populations randomly (Hughes et al. 1995). Building on links with minority ethnic community groups and individuals, the approach to sampling was twofold. Approximately half the sample was recruited using 'snowballing' methods. Research assistants, employed as fieldworkers, distributed questionnaires via community organisations or directly to individuals. Approximately, the other half of the sample comprised of participants 
who were approached in areas frequented by minority ethnic communities in Preston and Burnley, both on the cities university campuses (e.g., libraries and refectories) and locally within shopping centres and outside colleges. Given the sensitive nature of the study's aims, precautionary measures were taken to ensure the confidentiality and safety of the individuals recruited to participate in this study, including the provision of self-addressed envelopes so respondents could return questionnaires if they wished, without pressure from the researchers. The project was fully approved by the authors' institution's ethics committee and complies with British Psychological Society (BPS) ethics guidelines.

$<$ Insert Table 1 here $>$

\section{Materials and Measures}

A questionnaire booklet was designed, with all measures developed for the purpose of the current study. The questionnaire was available in four languages. The original English-language questionnaire was back-translated into Bengali, Urdu and Hindi.

Participants' perceptions of HBV were gauged by presenting 10 brief hypothetical scenarios [3] that depicted a number of situations in which HBV had clearly occurred or was strongly implied. The incidents described in these scenarios were loosely based on HBV cases widely reported in the British media, so to be deemed as feasible. To measure the degree to which HBV was endorsed per each scenario, after each of depiction, participants were asked to indicate the extent to which they approved of, or agreed with, the actions of the actors within the scenarios. For example, to measure approval of $\mathrm{HBV}$ victimisation in scenario 1, participants were asked "To what extent do you approve of Abdul's family's actions?" Responses to these questions were measured on a 5-point Likert scale, ranging from "disagree totally" to "agree totally". Participants were also prompted, after each of the 10 scenarios, to elaborate on their views about each scenario if they wished to do so. 
Using both close-ended and open-ended questions, participants were then asked to report on their own HBV experiences, the consequences of this victimisation on their health, and helpseeking for these incidents. As a prompt, participants were encouraged to elaborate on their responses. To gauge awareness of victim support services available in their local or regional area (Preston and Burnley), participants were presented with a list of six HBV and domestic violence support groups/agencies and asked to indicate if they were aware of these services and if they would use that service provider if needed in the future. A debriefing page was attached to the questionnaire, which included a range of telephone numbers and websites for services relating to HBV help and support.

\section{Data Analysis Plan}

Perceptions of HBV: Principal Components Analysis and reliability analysis (Cronbach's Alpha) were conducted on the 10 questions that related to each of the scenarios. This analysis created a reliable attitudinal measure of HBV perceptions. Two scales were created and used as dependent variables in subsequent analysis. Independent-tests then explored how perceptions of HBV differed in relation to gender and prior victimisation status. Some quotes made by participants who elaborated via the open-ended questions were included in this section to illustrate key points.

HBV Victimisation Experiences: Descriptive data from participant quotes regarding the scope of HBV victimisation were utilised in this section to illustrate experiences, in relation to reporting HBV to the police, and physical and mental health consequences.

Awareness of HBV Support Services: Descriptive data, again from participant quotes were utilised to highlight the awareness (or lack thereof) of help and support available for HBV victims in the study locale, and views about barriers to reporting or receiving support.

\section{Results}




\section{Principal Components Analysis and Reliability Tests}

With the aim of designing reliable measures to assess perceptions of HBV victimisation, the 10 questions relating to each of the hypothetical scenarios were subjected to Principal Components Analysis (PCA) with Varimax Rotation on SPSS Version 21. PCA is a statistical technique that explores the relatedness between questionnaire items in order to identify clusters of items, known as factors. Items that form a factor can then be totalled and presented as a coherent scale, which measures a construct labelled by the researcher based on the meaning of the items that relate to the factor (Field, 2013).

The results of this analyses show that the PCA model accounted for $53.56 \%$ of the variance, and isolated 2 factors with Eigenvalues greater than 1, comprising each of 5 items. Items on the first factor related to being forced into marriage or being unhappy and abused within marriage (but unable to leave in order to protect the family's honour). This factor was thus labelled "Forced Marriage". Testing for the reliability of this factor was conducted using Cronbach's Alpha. This factor was deemed highly reliable (0.79). The second factor related to having "unsuitable" relationships, being lesbian, having a child out of wedlock or otherwise displeasing the family. This factor was labelled "Dishonouring the Family", and revealed a good Cronbach's Alpha of 0.76 .

A total of each attitude scale was found by summing items in each factor. This gave a minimum score of 0 and maximum of 20 possible for each scale. A low score each scale denoted disagreement with the concept and a high score being condoning of it. A statistical investigation of the attitudes scales across the sample was then undertaken.

\section{Gender and Prior Victimisation Differences}


Overall means on each of the two attitude scales were very low; $0.96(\mathrm{SD}=2.09)$ for Forced Marriage, and $5.13(\mathrm{SD}=4.57)$ for Dishonouring the Family, thus the sample overall did not endorse attitudes supportive of HBV.

However, gender differences on the "forced marriage" scale were revealed and the strength of this difference was high $(\mathrm{t}(196)=4.47, \mathrm{p}<.001, \mathrm{~d}=0.64)$, such that males condoned forced marriage more than females $(1.90 \mathrm{v} 0.54 ; \mathrm{SD}=3.13 \mathrm{v} 1.16)$. No gender differences on the issue of "dishonouring the family" were found $(\mathrm{t}(199)=1.83, \mathrm{p}=.074, \mathrm{~d}=0.26)$.

Moreover, no differences were revealed between those having experienced HBV victimisation in the past (whether reported or not) and those that had not, on either perceptions of forced marriage $(\mathrm{t}(191)=1.69, \mathrm{p}=09, \mathrm{~d}=0.24)$ or on the issue of dishonouring the family $(\mathrm{t}(192)=0.51, \mathrm{p}=.48, \mathrm{~d}=0.07)$.

\section{Open-Ended Responses}

For illustrative purposes, open-ended responses were collected from participants and one key issue - that of the misuse of the concept of honour for violent means - is worthy of note because it demonstrates the strength of conviction that participants had about HBV and explains the low level of negative HBV attitudes shown in this sample.

Statements made by participants reflect the nature of views within the sample being very much against HBV. Participants spoke clearly on how negative they felt about the misuse of the concept of "honour". One participant, a 19-year-old Muslim female wrote: "I believe new generation is becoming more tolerant to acts that could be deemed as unhonourable [sic]. This could be due to Western society influence”. Another participant, also a 19-year-old Muslim female was blunt about her feelings toward the concept of honour, when violence committed in its name: 
"I think the attitude of honour is stupid, yes to an extent your family's izaat is important. However, what your family can do to protect their "honour" is bizarre, i.e. the cases of killing your daughter, getting her married off, like it's "honour" more important than your child... thankfully I have great parents, my mum being brought up from here has very good mentality, both my parents are religious but not cultural, my father avoids the marriage topic when it comes to his daughters".

\section{HBV Victimisation Experiences}

Overall, 180 participants (83.3\%) reported no direct experience of $\mathrm{HBV}$ victimisation. Of the $16.67 \%$ (31 participants; 13 male and 18 female) that had experienced such abuse, 10 males and 14 females had not reported it to anyone, whilst 3 males and 4 females had done so. Six participants reported their abuse to the local police; 2 participants felt positive about this experience, while 4 felt that their experience with the police was negative. Participants who reported a positive or negative experience with the police did not give reasons for their reactions, with only one person (a 22-year-old Muslim woman) commenting on the reporting of her HBV victimisation to the police. She said her experience was negative because they were not helpful or understanding. When asked how the police and other services can improve their agencies to the public seeking help for 'honour' crimes, she said that services need to educate (presumably themselves) and increase their cultural awareness.

As almost equal numbers of males and females had experienced HBV victimisation, the following results are not split by gender. When asked specific questions about the health consequences of $\mathrm{HBV}$, victims answered in a range of ways. Specifically, 11 of the 31 victims (35.5\%) who reported direct experience of HBV had hidden the injuries they had received from their spouse, family or community to protect their family's honour. As a consequence of HBV, 17 of the 31 victims (54.8\%) felt isolated from others, with 22 of the 31 (71.0\%) feeling that they 
could not confide in anyone about their victimisation. In terms of mental health issues, 21 of the 31 victims (67.7\%) reported feelings of anxiety. Further, 23 of the 31 victims $(74.2 \%)$ felt depressed, 10 (32.3\%) had self-harmed as a consequence of HBV and worryingly, 4 victims $(12.9 \%)$ had attempted suicide at the time the survey took place. Finally, 17 of the 31 victims (54.9\%) felt angry at the perpetrator and 7 (22.6\%) felt scared of him/her. Ten of the 31 victims $(32.3 \%)$ had run away from home as a result of HBV victimisation.

\section{Awareness of HBV Support Services}

The entire sample of 216 participants were asked about their awareness of support services for HBV victims in their local areas (i.e., Preston and Burnley) and how these services are currently perceived amongst ethnic minority communities in this locale. Some participants were very clear about the types of help that are needed to support victims of HBV, and to increase reporting, and suggested increased publicity by way of posters, leaflets, religious leaders enforcing that HBV is wrong, and better criminal justice for perpetrators. Some relevant quotes from participants are included within this section.

Generally, of the participants who answered the question about perceived barriers to receiving help for HBV victimisation (206 participants; 10 did not answer this question), 74 participants $(35.9 \%)$ said they were unsure and a further 49 participants $(23.8 \%)$ said that there was no way to prevent HBV. A further 40 participants (19.4\%) said fear would prevent a victim getting help. Other barriers included family and children (11 participants; 5.3\%), shame (10 participants; $4.9 \%$ ), and being punished for reporting ( 7 participants; $3.4 \%$ ). Of the $51 \%$ of the sample (206 participants) who answered the question on how services could be improved, 67 participants (32.5\%) said that awareness of the help and support available needs to be increased. Other responses included increasing education (7 participants; 3.4\%), ensuring confidentiality for victims (11 participants; 5.3\%), and increasing safety (6 participants; $2.9 \%$ ). Open-ended 
'Honour'-Based Violence

responses were particularly interesting as illustration of views on this issue. One 20-year-old Muslim male passionately stated, of how the police and service providers could improve: "To inform victims of what was done was wrong. To get religious leaders to condemn such acts. Publicly denounce the offenders who commit such evil. To inform the victims that it is not their fault, they are victims. To take a stand and fight back...'Honour' is nothing more than a pathetic excuse to justify abuse of one's loved ones...."

Another participant, a 42-year-old Muslim female, said that the issue of improving help and support was a very complex one and, "Unless you are in that situation, very hard to relate to the level of abuse. Policy makers should introduce survivors as mentors, and take their views into account." Service providers failing to understand the possible negative implications for victims by suggesting they go back to their families was mentioned by a 19-year-old female Muslim, who recounted a story of her friend's need to seek help from the local police:

"My friend sought help as she was afraid her family were taking her abroad to get married. She went to the local police. She found that they were very supportive - Took all necessary action and took her very seriously. However, the support worker (who was Asian) kept persuading her to go back to her family which she found very uncomforting [sic]. Also, he assured her that he wouldn't tell her family her whereabouts or other info but ended up doing so -- It was OK in her case, but if he did that with someone else, it may be dangerous".

Interestingly, when asked if aware of the six victim services for HBV in the local area, $60.2 \%$ of the whole sample of 216 participants said while they were unaware of the range of services, $69.8 \%$ of these participants said they would be willing to use at least one service if they ever needed to.

\section{Discussion}


This is the first study to explore attitudes towards HBV, victimisation experiences and awareness of support services in a local community of South Asian males and females in the north of England. The findings of this investigation contributes to the limited literature available on HBV in local British communities. Attitudes towards HBV were explored using principal components analysis, which revealed two attitudinal themes: perceptions of forced marriage and perceptions relating to dishonouring the family. When these two attitudinal aspects were tested across participant gender and victimisation status, only one difference was revealed, that males were more condoning of forced marriage than were females. Yet, unlike attitudes towards domestic violence in comparable populations, tolerance of HBV was not clearly gendered. Instead, across both factorial-components, all participants responded in a way that showed low endorsement of attitudes that would support HBV, with some participants bluntly stating that the concept of using violence to defend honour, to them, was inexplicable.

Of the predominately young, single, childfree/childless and well-educated participants in this study, $17 \%$ reported direct experience of $\mathrm{HBV}$ victimisation. A number of detrimental effects were reported that ranged from feelings of isolation to physical injuries, as well as psychological distress resulting in attempted suicide and running away from home. The present study showed that while HBV victimisation was not widely reported in this sample, when participants did experience this form of abuse, it caused significant harm in some instances. Additionally, HBV victimisation was reported at a similar rate by the males and females who participated in this study. This finding reflects the visibility of male HBV victimisation and forced marriage reports in the UK. For example, of the 1,267 and 1,220 forced marriages reported to the Forced Marriage Unit (2016) [4] in 2014 and 2015 respectively, there was an approximate 20:80 percent male-to-female ratio. 
While approximately one-sixth of this sample reported at least one HBV victimisation experience, this prevalence rate was far lower than expected. It is, therefore, reasonable to suggest that the premise of this investigation may have been unduly influenced by cultural stereotypes. This association has become increasingly salient since 2016, with increasingly hostile, right-wing rhetoric in media reports that openly target Muslim communities in perpetuating the unsupported myth that Islam promotes the use of violence (Ahmed \& Matthes, 2016).

\section{Limitations of current study}

While the strength of this small-scale community study is its potential to facilitate muchneeded larger-scale research into HBV, a related methodological drawback is the use of a localised, non-representative, convenience sample as this limits opportunities to generalise the findings to other populations across the UK. Indeed, participants in this study had a good level of education, were mostly unmarried and childfree/childless, and thus not wholly representative of South Asians in Britain (Bagguley \& Hussain, 2007). Although some studies report those with lower educational backgrounds hold more supportive attitudes towards HBV (e.g., Eisner \& Ghuneim, 2013), there is evidence to suggest that minimisation of HBV occurs across many communities in Britain, regardless of educational or economic status (Brandon \& Hafez, 2010).

Other methodological constraints include the use of imprecise measures to examine HBV victimisation. Upon reflection, by adhering to stringent ethical guidelines, the measures used were ambiguous and over-cautious: firstly, only one direct question was presented: "If you have been a victim of HBV, did you report the violence?" Secondly, the 10 hypothetical scenarios presented to participants did not encapsulate a wide range of $\mathrm{HBV}$ experiences beyond those described (e.g., forced marriage; in a relationship with someone from a different religious; in, or rumoured to be in, a gay or lesbian relationship) thus prevalence of HBV victimisation is likely 
to have been higher. It is also noteworthy that the victim's gender in each scenario and participants' attitudes towards homosexuality may have biased their responses.

\section{Directions for future studies}

Prospective studies may find value in measuring the influence of acculturation on perceptions of $\mathrm{HBV}$, as there is evidence that this influences South Asian men's attitudes towards violence against women (Bhanot \& Senn, 2007). Some efforts could also be made to disentangle a general approval of interpersonal violence from violence committed in the name of so-called 'honour', as research has found these to be correlated when gauging perceptions of HBV in a Latino population (see Dietrich \& Schuett, 2013). Clarity of this issue in South Asian populations would give strength to arguments that violence committed in the name of so-called 'honour' is no different to other incidents of domestic abuse (Chesler, 2009), or at least that the use of violence is often a justified means of controlling Asian women and children in the UK (Macey, 1999). Also, as the data for this study was unintentionally gathered from a predominately Islamic sample, there is clear scope for future studies to investigate what role religion plays in the conceptualisation of 'izzat' and the endorsement of HBV. It would also be useful to study other religious and ethnic communities to explore the link between religion, ethnicity and gender relations, thus increasing the likelihood of HBV being addressed more effectively in immigrant populations in the UK (Korteweg \& Yurdakul, 2009). Certainly, this would go some way to addressing Chesler's (2016) concern that academic research "whitewashes" HBV crimes in Muslim communities. In addition, while the results of the current study were enriched by using quotes made by participants for illustrative purposes, it would be advantageous for future studies to collect qualitative data on HBV victimisation to enhance the understanding of this topic from participants' own words.

\section{Recommendations for intervention and practice}


Notable efforts have been made to develop reliable HBV risk assessment guides to inform risk management approaches within (a) the criminal justice system to aid law enforcement and (b) as part of the health and welfare system to improve service delivery for victims. For example, the PATRIARCH (Belfrage, Strand, Ekman \& Hasselborg, 2012), developed in Sweden, may be a useful exemplar for efforts to develop reliable guidelines in the UK. Support for more robust professional guidance is found in a comparative analysis of 211 domestic violence cases, recorded by Lancashire Constabulary; the police recorded South Asian victims at lower risk than all other ethnicities compared to an independent local Victim Support group, who found no difference in level of risk across ethnic groups (Khan et al. 2015). This discrepancy, in part, was thought to reflect the police's use of a potentially invalid yet widely used risk assessment tool (i.e., ACPO-DASH), which currently contains a number of untested questions, of which only two relate specifically to HBV to assess level of victim risk. The need for reliable, culturally-sensitive risk assessment for 'honour' crimes was demonstrated in the present study as, despite the majority of the sample reporting no HBV victimisation experiences, nearly one-quarter of the sample (19.4\%) indicated that 'fear' and 'shame' $(4.9 \%)$ was a barrier to seeking professional help. Also, that of the 31 participants who reported HBV victimisation, one-third reported hiding their injuries to protect family 'honour', over a half felt isolated, and just under three-quarters thought that they could not confide in anyone. This finding is in line with previous research that found concerns about dishonour (i.e., izzat) and shame (i.e., sharam) were associated with a lack of engagement with healthcare services for South Asian female populations in the UK (Gilbert, Gilbert \& Sanghera, 2004). In Sweden, notable attempts have been made to re-evaluate service provisions and delivery for HBV victims from diasporapopulations with concrete recommendations to recognise these victims' need to protect 'family honour' (e.g., Alizadeh, Törnkvist, \& Hylander, 2011). These efforts seem particularly relevant 
in the context of studies that suggest nursing staff, in-training to work within healthcare services, would condone the use of violence, and even murder, if committed to protect 'honour' (cf. Can \& Edirne, 2010). This suggests an urgent need for agencies in the UK to review current emergency responses and welfare support so that they consider such fundamental, culturallydefined concepts such as the role of 'honour' in designing and delivering services for South Asian populations; this is a recommendation identified by other studies in the north of England (Anitha, 2010). This is even more salient when considering the findings of health practitioners, that note the link between fears of disclosing HBV with self-harm and suicide in British Asian females, which is notably higher than comparable female groups in Britain (Husain, Waheed, \& Husain, 2006). From a service provision perspective, a large proportion of the participants in this study were not aware of general or specialised HBV intervention services available to them in their local or wider areas. This suggests that agencies could explore ways in which to promote their services more publically in the north of England.

The results of this investigation suggest that HBV victimisation occurs within northern England communities, and that it is experienced by young, females and males from South Asian diasporic populations. Despite a range of negative health consequences related to their experiences, many participants expressed fear in seeking help from external agencies, as well as personal barriers, including 'shame', but were able to suggest ways in which services could be improved. Future investigations should bear in mind the limitations of this study, and explore the issues discussed in this paper. Specifically, that local studies could be subsumed within largerscale investigations to allow generalisations to be made.

\section{References}

Ahmed, S., \& Matthes, J. (2016). Media representation of Muslims and Islam from 2000 to 2015: A meta-analysis. International Communication Gazette, 1748048516656305. 
'Honour'-Based Violence

Al Gharaibeh, F. M. (2016). Debating the role of custom, religion and law in 'honour' crimes: implications for social work. Ethics and Social Welfare, 10(2), 122-139. doi: 10.1080/17496535.2016.1155632.

Alizadeh, V., Törnkvist, L., \& Hylander, I. (2011). Counselling teenage girls on problems related to the 'protection of family honour' from the perspective of school nurses and counsellors. Health \& Social Care in the Community, 19(5), 476-484.

Aplin, R. (2017). Exploring the role of mothers in 'honour' based abuse perpetration and the impact on the policing response. In Women's Studies International Forum,60, 1-10.

Pergamon.

Bagguley P. \& Hussain Y. (2007). The role of higher education in providing opportunities for South Asian women. Report for the Joseph Rowntree Foundation, published by Policy Press: The Policy Press.

BBC News. (2011). 'Honour' attack numbers revealed by UK police forces. Retrieved, 2014, from http://www.bbc.co.uk/news/uk-16014368

Belfrage, H., Strand, S., Ekman, L., \& Hasselborg, A. (2012). Assessing risk of patriarchal violence with honour as a motive: Six years' experience using the PATRIARCH checklist. International Journal of Police Science \& Management, 14(1), 20-29.

Bhanot, S., \& Senn, C. Y. (2007). Attitudes towards violence against women in men of south Asian ancestry: Are acculturation and gender role attitudes important factors? Journal of Family Violence, 22(1), 25-31.

Brandon, J., Hafez, S., \& England Centre for Social Cohesion London. (2010). Crimes of the community: Honour-based violence in the UK. Centre for Social Cohesion London. 
Can, M., \& Edirne, T. (2011). Beliefs and attitudes of final-year nursing students on honour crimes: A cross-sectional study. Journal of Psychiatric and Mental Health Nursing, 18(8), 736-743.

Census Statistics Bulletin (2013). 2011 Census: Key statistics and quick statistics for local authorities in the United Kingdom. Office for national statistics.

Chesler, P. (2009). Are honour killings simply domestic violence? The Middle East Quarterly, $16(2), 61-69$

Chesler, P. (2010). Worldwide trends in honour killings. The Middle East Quarterly, XVII(2), $17(2), 1-11$.

Chesler, P. (2015). When women commit honour killings. Middle East Quarterly. 22(4).

Chesler, P. (2016). How academia whitewashes Muslim honour killings. Middle East Forum. Retrieved, 2016 www.meforum.org/5867/how-academia-whitewashes-honour-killings. ComRes, (2012). BBC Panorama Honor Crime Survey. A survey of young British Asians conducted on behalf of BBC Panorama. Retrieved from http://www.comresglobal.com/polls/bbc-panorama-honor-crime-survey/

Crime Prosecution Service. Honour based violence. Retrieved, 2014, Retrieved from http://www.cps.gov.uk/legal/h_to_k/honour_based_violence_and_forced_marriage/

Dietrich, D. M., \& Schuett, J. M. (2013). Culture of honour and attitudes toward intimate partner violence in Latinos. Sage Open, 3(2)

Dyer, E. (2015). Honour Killing in the UK. The Henry Jackson Society. Retrieved from http://henryjacksonsociety.org/wp-content/uploads/2015/01/Honour-Killings-in-the-UK.pdf.

Eisner, M., \& Ghuneim, L. (2013). Honour killing attitudes amongst adolescents in Amman, Jordan. Aggressive Behavior, 39(5), 405-417.

Field, A. (2013). Discovering Statistics using IBM SPSS Statistics. London: Sage. 
'Honour'-Based Violence

Forced Marriage Unit (2016). Forced Marriage Statistics for 2014 and 2015. Retrieved from www.gov.uk/forced-marriage

Gangoli, G., McCarry, M., \& Razak, A. (2009). Child marriage or forced marriage? South Asian communities in North East England. Children \& Society, 23(6), 418-429.

Gilbert, P., Gilbert, J., \& Sanghera, J. (2004). A focus group exploration of the impact of izzat, shame, subordination and entrapment on mental health and service use in South Asian women living in Derby. Mental Health, Religion \& Culture, 7(2), 109-130.

Grzyb, M. A. (2016). An explanation of honour-related killings of women in Europe through Bourdieu's concept of symbolic violence and masculine domination. Current Sociology, 64(7), 1036-1053.

Hughes, A. O., Fenton, S., Hine, C. E., Pilgrim, S., \& Tibbs, N. (1995). Strategies for sampling black and ethnic minority populations. Journal of Public Health Medicine, 17(2), 187-192.

Husain, M. I., Waheed, W., \& Husain, N. (2006). Self-harm in British South Asian women: psychosocial correlates and strategies for prevention. Annals of General Psychiatry, 5(1), 1 Iranian and Kurdish Woman's Right Organisation (IKWRO). (2014). Postcode lottery: police recording of reported 'honour' based violence. London, UK.

Khan, R. (2007). Honour-Related Violence (HRV) in Scotland: A cross-and multi-agency intervention involvement survey. Internet Journal of Criminology, 1-8.

Khan, R. (2017). Attitudes towards 'honor' violence and killings in collectivist cultures: Gender differences in Middle Eastern, North African, South Asian (MENASA) and Turkish populations. In J. L. Ireland, P, Birch, \& C. A. Ireland (Eds.), International Handbook in Aggression, Chapter 6, Routledge.

Khan, R., Willan, V. J., Lowe, M., Robinson, P., Brooks, M., Irving, M., ... \& Bryce, J. (2015). Assessing victim risk in cases of violent crime. Safer Communities, 14(4), 203-211. 
Korteweg, A., \& Yurdakul, G. (2009). Islam, gender, and immigrant integration: Boundary drawing in discourses on honour killing in the Netherlands and Germany. Ethnic and Racial Studies, 32(2), 218-238.

Macey, M. (1999). Class, gender and religious influences on changing patterns of Pakistani Muslim male violence in Bradford. Ethnic and Racial Studies, 22(5), 845-866.

Roberts, K. (2014). Towards a psychologically oriented motivational model of honour-based violence. In A. K. Gill, C. Strange, \& K. Roberts (Eds.), Honour killing and violence: Theory, policy and practice (pp. 69-88). New York: Palgrave Macmillan.

Schlytter, A., \& Linell, H. (2010). Girls with honour-related problems in a comparative perspective. International Journal of Social Welfare, 19(2), 152-161.

Shaikh, M. A., Shaikh, I. A., Kamal, A., \& Masood, S. (2010). Attitudes about honour killing among men and women - perspective from Islamabad. J Ayub Med Coll Abbottabad, 22(3), $38-41$.

[1] The terms 'honour'-based violence, 'honour' crimes and 'honour' killings are used throughout for succinctness; these terms differ across cited sources but they all refer to crimes committed in the name of so called 'honour'.

[2] These terms, which refer to concepts of honour, are of great social value in many South Asian cultures.

[3] Available by request from corresponding author

[4] The Forced Marriage Unit is a joint Foreign and Commonwealth Office and Home Office unit working on the Government's forced marriage policy, outreach and casework. 
'Honour'-Based Violence

Table 1

Demographic breakdown of participants $(n=216)$ in this British South Asian sample

\begin{tabular}{|c|c|}
\hline Demographic Breakdown & $\%$ \\
\hline \multicolumn{2}{|l|}{ Language Spoken } \\
\hline English +1 other & 86.6 (mainly either Urdu or Guajarati) \\
\hline No English & 1.9 \\
\hline \multicolumn{2}{|l|}{ Education } \\
\hline Higher Education (college or above) & 91.1 \\
\hline Schooled up to age 16 & 7.9 \\
\hline No schooling & 0.9 \\
\hline \multicolumn{2}{|l|}{ Occupational Status } \\
\hline Student & 71.0 \\
\hline Working full time & 9.3 \\
\hline Working part time & 0.3 \\
\hline Unemployed & 4.7 \\
\hline Homemaker & 3.7 \\
\hline Retired or Other & 1.0 \\
\hline \multicolumn{2}{|l|}{ Relationship Status } \\
\hline Single & 75.5 \\
\hline Separated/divorced & 0.9 \\
\hline Dating & 11.2 \\
\hline Married & 10.2 \\
\hline Engaged & 0.5 \\
\hline Did not state & 1.0 \\
\hline \multicolumn{2}{|l|}{ Number of Children } \\
\hline 0 & 89.9 \\
\hline 1 & 3.3 \\
\hline 2 & 2.8 \\
\hline 3 & 2.8 \\
\hline 4 & 0.5 \\
\hline $5+$ & 1.5 \\
\hline
\end{tabular}

\section{Language Spoken}

English +1 other

English

Education

Higher Education (college or above)

Schooled up to age 16

7.9

0.9

Occupational Status

Student

0.3

3.7

1.0

75.5

11.2

89.9

2.8

1.5 